\title{
COMPLETELY PRIME HYPERIDEALS OF TERNARY SEMIHYPERGROUPS
}

\author{
Y. Sarala ${ }^{1 *}$, P. Seetha Mani ${ }^{1}$, M. Gulistan ${ }^{2}$ \\ AND \\ G. JAYA LALITHA ${ }^{1}$ \\ ${ }^{1}$ Department of Mathematics \\ K.L.E.F, Vaddeswaram, Guntur Dt., A.P., India \\ ${ }^{2}$ Department of Mathematics \\ Hazara University, Pakistan \\ e-mail: saralayella1970@gmail.com
}

\begin{abstract}
In this article, we introduce the notions of pseudosymmetric hyperideals and globally idempotent ternary semihypergroups and present various examples for them. We prove that if a ternary semihypergroup is globally idempotent, then every maximal hyperideal is a prime hyperideal. Also we study some properties of prime, completely prime and pseudosymmetric hyperideals of a ternary semihypergroup and characterize them. The interrelation among them is considered in ternary semihypergroups.
\end{abstract}

Keywords: pseudosymmetric, globally idempotent, leftsimple ternary semihypergroup.

2010 Mathematics Subject Classification: 20N20, 20M12.

\section{REFERENCES}

[1] A. Anjaneyulu, Structure and ideal theory of semigroups-thesis, 22 (1980). doi:10.1007/BF02572805

[2] A. Basar, Application of $(m, n)$-gamma hyperideals in charectorization of LA-gamma semihypergroups, Discuss. Math. General Alg. and Appl. 39 (2019) 135-147. doi:10.7151/dmgaa.1304

[3] A.H. Clifford and G.B. Preston, The algebraic theory of Semigroups, Amer. Math. Soc. Providence I (1961).

\footnotetext{
${ }^{*}$ Corresponding author.
} 
[4] A. Cayley, On the theory of linear transformations, Cambridge Math. J. 4 (1845) 193-209.

[5] P. Corsini and V. Leoreanu, Applications of hyperstructures and theory, Adv. Math. Kheswer Acad. Publisher, (2003). doi:10.1007/978-1-4757-3714-1

[6] B. Davvaz and V. Leoreanu, Hyperring Theory and Applications (Inter. Academ. Press, USA, 2007).

[7] B. Davvaz, W.A. Dudek and T. Vougiouklis, A generalisation of n-ary algebraic systems, Commun. Algebra 37 (2009) 1248-1263.

doi:10.1080/00927870802466835

[8] B. Davvaz and V. Leoreanu, Binary relations on ternary semihypergroups, Commun. Algebra 38 (2010) 3621-3636. doi:10.1080/00927870903200935

[9] V.N. Dixit and S. Dawan, A note on quasi and biideals in ternary semigroups, Int. J. Math. Sci. 18 (1995) 501-508. doi:10.1155/S0161171295000640

[10] W. Dörnte, Untersuchungen über einen verallgemeinerten Gruppenbegriff, Math. Z. 29 (1929) $1-19$. doi:10.1007/BF01180515

[11] W.A. Dudek, On divisibility in n-semigroups, Demonstratio Math. 13 (1980) $355-367$.

[12] W.A. Dudek and I. Grozdzinska, On ideals in regular n-semigroups, Math. Bull. 3 (1980) 29-30.

[13] K. Hila, B. Davaaz and K. Naka, On hyperideals structure of ternary semihyper groups, Iranian. J. Math. Sci. Inform. 9 (2014) 81-98.

[14] M. Karpranov, L.M. Gelfand and A. Zelevinskili, Discriminant Resultants and Multidimensional Determinants (Birkhauser Berlin, 1994).

[15] R. Kerner, Ternary algebraic structures and their applications in physics, Universite Pierre-et-Marie-Curie, (1995), arXiv:math-ph/0011023.

[16] D. Lehmer, A ternary analogue of abelian groups, Amer. J. Math. Sci. 59 (1972) 329-338.

[17] F. Marty, Sur une generalisation de la notion de group, 8th Congress Math. Scandinaves, Stockholm, Sweden (1934) 45-49.

[18] K. Naka and K. Hila, Some properties of hyper ideals in ternary semihypergroup, Math. Slovaca 63 (2013) 449-468. doi:10.2478/s12175-013-0108-3

[19] K. Naka and K. Hila, Regularity of ternary semihypergroups, Quasigroups and Related Systems 25 (2017) 291-306. 
[20] L. Nichefranca and K.P Shum, Pseudo symmetric ideals of semigroup and their radicals, Czech. Math. J. 48 (1998) 727-735. doi:10.1023/A:1022439706828

[21] D. Ramakotaiah and A. Anjaneyulu, On a class of semigroups, Simon Stevin 54 (1980) 241-249.

[22] F.M. Sioson, Ideal theory in ternary semigroups, Math. Japonica 10 (1965) 63-64.

[23] M. Shabir and Sk. Bashir, Prime ideals in ternary semigroups, Asian Eur. J. Math. 2 (2009) 141-154. doi:10.1142/S1793557109000121

[24] Y. Sarala, A. Anjaneyulu and D. Madhusudana Rao, Pseudo symmetric ideals in ternary semigroups, Internat. Ref. J. Eng. Sci. 1 (2012) 33-43.

[25] Y. Sarala, A. Anjaneyulu and D. Madhusudana Rao, Ideals in ternary semigroups, Internat. J. Math. Eng. 203 (2013) 1950-1968.

[26] T. Vougiouklis, Hyper structures and their representations (Hadronic Press Inc, Palm Harbor, USA, 1994).

Received 15 December 2019

Revised 25 February 2020

Accepted 13 July 2020 